\title{
Manejo da desfolha de duas variedades de trevo-persa cultivadas em solo hidromórfico
}

\section{Daiane Cristina Sganzerla ${ }^{1}$, Pedro Lima Monks ${ }^{2}$, Gabriel da Silva Lemos ${ }^{3}$, Carlos Eduardo da Silva Pedroso ${ }^{2}$, Vivian Brusius Cassal ${ }^{2}$, Maurício Gonçalves Bilharva ${ }^{4}$}

\author{
1 Doutoranda do Programa de Pós-Graduação em Zootecnia FAEM/UFPEL, Pelotas, RS. Bolsista CAPES. \\ 2 Departamento de Zootecnia/Universidade Federal de Pelotas. \\ ${ }^{3}$ Graduando em Agronomia/Universidade Federal de Pelotas. \\ 4 Graduando em Agronomia/Universidade Federal de Pelotas. Bolsista FAPERGS
}

RESUMO - Foram estudados os efeitos de três frequências e duas intensidades de desfolhação nas características morfogênicas e estruturais, na produção de forragem e na relação folha/caule de duas variedades de trevo-persa (Trifolium resupinatum L. var. resupinatum Gib \& Belli. cv. Kyambro e var. majus Boiss cv. BRS Resteveiro). O delineamento utilizado foi de blocos completos ao acaso, em esquema fatorial $3 \times 2 \times 2$, com cinco repetições. Foram avaliadas as seguintes variáveis: taxa de aparecimento de folhas, filocrono, taxa de alongamento e alargamento de folíolos, largura e comprimento de folíolos, número de ramificações, altura de planta, número de folhas vivas abertas, produção de matéria seca total e relação folha/caule. Apesar de a pastagem apresentar maior número de folhas vivas em intervalos de desfolhação maiores e a maior produção de forragem ter sido obtida na altura residual de $5 \mathrm{~cm}$ e no intervalo de 6 folhas surgidas, cortes mais frequentes proporcionam melhora da relação folha/caule, maior número de ramificações, maior taxa de surgimento de folhas e maior tamanho de folíolos

Palavras-chave: desfolhação, leguminosa forrageira, morfogênese, Trifolium resupinatum L.

\section{Defoliation management in two varieties of persian clover cultivated on hidromorfic soil}

\begin{abstract}
The effects of three frequencies and two intensities of defoliation on the morphogenic and structural characteristics, in the herbage production and leaf/stem ratio of two varieties of persian clover (Trifolium resupinatum L. var. resupinatum Gib \& Belli. cv. Kyambro and Trifolium resupinatum var. majus Boiss cv. BRS Resteveiro) were studied. The experimental design consisted of complete randomized blocks in a $2 \times 3 \times 2$ factorial arrangement, with five replications. The following variables were evaluated: leaf appearance rate, phyllochron, leaflet extension and elongation rate, leaflet width and length, number of ramifications, plant height, number of open live leaves, total dry matter production and leaf/stem ratio. Although the forage presented higher number of live leaves in bigger defoliation intervals and the higher forage production was obtained in the residual height of $5 \mathrm{~cm}$ and in the interval of 6 leaves appearing, more frequent cuttings provide improvement of the leaf/stem ratio, higher number of ramifications, higher leaf appearance rate and bigger leaflet size.
\end{abstract}

Key Words: fall, forage leguminous, morphogenesis, Trifolium resupinatum L.

\section{Introdução}

A utilização de pastagens cultivadas em solos hidromórficos tem sido um grande desafio. Neste caso, as espécies forrageiras devem suportar níveis hídricos superiores a $100 \%$ da capacidade de campo, ocasionando falta de oxigênio para a respiração e o desenvolvimento das raízes. $\mathrm{O}$ arroz irrigado, cultura de grande importância no Rio Grande do Sul, se adapta muito bem nestas áreas por ter capacidade de transferir oxigênio atmosférico a partir das folhas e do caule para as raízes, por meio de uma estrutura denominada aerênquima. Contudo, a pesquisa tem buscado espécies forrageiras adaptadas a esse ambiente para fazer parte de um sistema de rotação arroz-pastagem. Trifolium resupinatum L. (trevo-persa), uma leguminosa anual de estação fria nativa de países mediterrâneos e da Europa, mostra-se produtiva ( 6 a $9 \mathrm{t} \mathrm{MS} / \mathrm{ha}$ ) em áreas onde a umidade do solo é alta, pois possui caules ocos que a tornam bastante resistente à falta de oxigênio no solo, sendo assim uma opção forrageira interessante para rotação com arroz. Esta espécie, além de apresentar alto valor nutritivo, em torno de 16 a 21\% de proteína bruta, 24 a 45\% de FDN e 63 a $78 \%$ de digestibilidade in vitro da matéria orgânica (MSU, 2010), também é capaz de fixar nitrogênio no solo e 
este nitrogênio ser aproveitado pela cultura subsequente. Segundo Scivittaro et al. (2007), em trabalho utilizando diferentes coberturas do solo como fonte de nitrogênio para produção orgânica de arroz irrigado, o trevo-persa acumulou $92,7 \mathrm{~kg} /$ ha de $\mathrm{N}$ e a produção sucessiva de grãos do arroz irrigado atingiu $7.193 \mathrm{~kg} / \mathrm{ha}$. Além disso, possui importante ressemeadura natural, permitindo, assim, sua perenidade na área (Reis, 2007) e diminuição dos custos com a implantação da pastagem. No entanto, informações sobre o adequado manejo de desfolha desta planta em solos hidromórficos do Sul do Brasil são praticamente inexistentes. Desse modo, para determinação mais adequada da intensidade e do período entre desfolhas, torna-se fundamental o conhecimento do comportamento de variáveis morfogênicas e estruturais, como taxa de aparecimento e senescência de órgãos, alongamento e longevidade de folhas, número máximo de folhas vivas, aparecimento e morte de ramos (Mazzanti, 1997). Assim, realizou-se este estudo com os objetivos de estudar a pastagem de trevopersa sob diferentes frequências e intensidades de desfolha e verificar o efeito desses fatores nas características morfogênicas e estruturais e na produção de forragem.

\section{Material e Métodos}

O trabalho foi desenvolvido em solo hidromórfico, classificado como Planossolo Háplico Eutrófico Solódico, pertencente à unidade de mapeamento Pelotas (Streck et al., 2008), com a seguinte composição química na camada de 0 a $20 \mathrm{~cm}$ : $\mathrm{pH}$ em $\mathrm{H}_{2} \mathrm{O}: 5,0 ; \mathrm{pH}$ SMP: 6,3; $\mathrm{P}: 50 \mathrm{mg} / \mathrm{kg}$; $\mathrm{K}: 119 \mathrm{cmol}_{\mathrm{c}} \mathrm{dm}^{-3}$; MO: 1,9\%; Al: 0,5 $\mathrm{cmol}_{\mathrm{c}} \mathrm{dm}^{-3}$; $\mathrm{Ca}$ : $0,8 \mathrm{cmol}_{\mathrm{c}} \mathrm{dm}^{-3} ; \mathrm{Mg}: 0,4 \mathrm{cmol}_{\mathrm{c}} \mathrm{dm}^{-3} ;$ e argila: $7 \%$. Antes do plantio, o solo foi devidamente corrigido com calcário dolomítico, com base na interpretação da análise do solo, em quantidade correspondente a 1,8 t/ha. Não foram necessários acréscimos de fósforo e potássio para o desenvolvimento da cultura, já que os níveis desses elementos eram elevados.

As sementes foram escarificadas, inoculadas com inoculante específico e semeadas em copos plásticos (30/4/2008) para o posterior plantio, em função da reduzida quantidade de semente disponível. Após permanência em casa-de-vegetação por 30 dias, em maio de 2008, as mudas foram transplantadas para o campo em parcelas medindo $1,0 \times 0,90 \mathrm{~m}$, com linhas espaçadas a $20 \mathrm{~cm}$ e com $15 \mathrm{~cm}$ de distância entre as plantas. O estabelecimento da pastagem ocorreu em agosto. A necessidade do transplante das mudas atrasou o momento da primeira desfolha, provavelmente pelo período de adaptação das plantas ao novo ambiente produtivo (Carámbula, 2004). Desse modo, o estabelecimento que ocorreria em aproximadamente três meses a partir da semeadura ocorreu em quatro meses. Assim, em agosto de 2008, as plantas foram cortadas nas intensidades pré-estabelecidas como tratamento $(5$ e $10 \mathrm{~cm}$ de altura em relação ao nível do solo) e, a partir de então, o período experimental se estendeu até início de novembro de 2008. Ressalta-se que a semeadura do trevo-persa ocorre no outono e o início do florescimento se dá aos 135-165 dias após a semeadura (Suttie, 1999).

Os tratamentos corresponderam a duas variedades de trevo-persa (Trifolium resupinatum L. var. resupinatum Gib \& Belli. cv. Kyambro e var. majus Boiss cv. BRS Resteveiro), duas intensidades e três frequências de desfolhação, em delineamento de blocos completos ao acaso, com esquema fatorial $2 \times 2 \times 3$, com quatro repetições. As intensidades de desfolhação foram 5 e $10 \mathrm{~cm}$ em relação ao nível do solo, de modo que a menor intensidade, conforme a literatura, praticamente não causa prejuízos à persistência da forrageira (Stockdale, 1994). Já a maior intensidade foi determinada como a metade da anteriormente citada. As frequências de desfolhação foram os intervalos entre cortes necessários para o surgimento de 4,5 e 6 folhas (ponta visível dos folíolos). O intervalo entre desfolhas intermediário coincide com relatos da literatura que apontam melhor produção de forragem em intervalos de aproximadamente 30 dias. O maior intervalo foi determinado de acordo com pesquisas que relatam que, a partir de intervalos de aproximadamente 6 semanas (42 dias), ocorre maior perda de matéria seca por mortalidade de folhas. Já o menor intervalo foi definido para observar se ocorreria melhora da relação folha/caule sem comprometimento da persistência do pasto. Optou-se pela escolha dos intervalos de corte, em função do número de folhas surgidas, ao invés do número de dias, já que o número de folhas vivas é a fração mais valiosa da pastagem.

Para avaliação das variáveis morfogênicas e estruturais, foram marcadas duas ramificações, representativas, por parcela com fio colorido. Foram feitas duas avaliações por semana, com intervalos de 3 a 4 dias durante os períodos entre cortes, para estimativas das seguintes variáveis: taxa de surgimento de folhas $(\mathrm{TSF}=$ folhas/ramificação/grausdia), obtida pela relação entre o número de folhas surgidas por ramificação e a soma térmica do período de avaliação; taxa de alargamento de folíolos (TALAF $=\mathrm{cm} /$ ramificação/ graus-dia), relação entre o somatório de todo alargamento das lâminas foliares $(\mathrm{cm})$ e a soma térmica do período de avaliação; taxa de alongamento de folíolos (TALOF = $\mathrm{cm} /$ ramificação/graus-dia), relação entre o somatório de todo alongamento das lâminas foliares $(\mathrm{cm})$ e a soma térmica do período de avaliação; filocrono (FIL = soma térmica/ 
folha/ramificação), inverso da taxa de aparecimento de folhas; comprimento final de folíolos (CFF), calculado como o comprimento médio das lâminas foliares de todos os folíolos expandidos e em expansão presentes em uma ramificação, mensuradas no folíolo central; largura final de folíolos (LFF), estimada como a largura média das lâminas foliares de todos os folíolos expandidos e em expansão presentes em uma ramificação, mensuradas no folíolo central; número de folhas vivas abertas por ramificação (NFVA), média do número de folhas vivas abertas, em expansão e expandidas por ramificação durante o período de avaliação; número total de ramificações (NTR = ramificações $/ \mathrm{m}^{2}$ ), contagem do número de ramificações totais em cada planta, antes e após os cortes; altura final de plantas (AFP), medida utilizando-se régua graduada em centímetros, sendo mensuradas duas alturas por parcela.

Além disso, em cada parcela, foi coletada uma área de $0,5 \mathrm{~m} \times 0,5 \mathrm{~m}$ de forragem, que posteriormente foi dividida em duas partes iguais: uma para quantificar a produção de matéria seca e a outra para determinar a relação folha/caule. As amostras para determinação da produção de forragem foram secas em estufa com ventilação forçada de ar a $65^{\circ} \mathrm{C}$ por aproximadamente 72 horas, até peso constante. $\mathrm{Na}$ outra parte da amostra coletada, as plantas foram separadas em folíolos + pecíolos (folhas) e caules para determinação da relação folha/caule.

Para o cálculo da soma térmica, foi utilizada a seguinte equação:

$\sum t=\left[\left(\frac{T \max +T \min }{2}\right)-T b\right]$

em que $\Sigma \mathrm{t}=$ soma térmica; $\operatorname{Tmax}=$ a temperatura máxima; $\mathrm{Tmin}=$ temperatura mínima; $\mathrm{e} \mathrm{Tb}=$ temperatura base. Foi utilizada a temperatura para início de florescimento de $5,7^{\circ} \mathrm{C}$ como temperatura base (Iannucci et al., 2008).

Os dados foram submetidos à análise de variância e as médias comparadas pelo teste Tukey $(\mathrm{P}<0,05)$.

\section{Resultados e Discussão}

As características morfogênicas e estruturais do trevo-persa não apresentaram interação entre os fatores estudados. Não foram verificadas diferenças entre as duas variedades para variáveis morfogênicas, estruturais e de produção de forragem, o que indica grande similaridade entre essas cultivares submetidas ao manejo de desfolha. Embora em crescimento livre Erdemli et al. (2007), na Turquia, relataram que linhagens destas variedades apresentaram diferenças morfológicas quanto ao comprimento e à largura de folíolos, à altura de plantas, ao diâmetro do caule e ao número de folhas na ramificação principal. Segundo os mesmos autores, essas diferenças também podem ser explicadas por efeitos de fatores ambientais intrínsecos de cada localização geográfica.

A taxa de aparecimento de folhas (TApF) foi influenciada apenas pela frequência de desfolha e foi menor em cortes menos frequentes, consequentemente, $\mathrm{o}$ filocrono (intervalo de tempo entre o surgimento de duas folhas consecutivas - FIL) foi maior nos mesmos intervalos, uma vez que é obtido pelo inverso da TApF (Tabela 1).

$\mathrm{O}$ menor filocrono significou menos graus-dia necessários para o surgimento de duas folhas consecutivas. Desse modo, a energia disponível para a planta foi mais bem aproveitada para o aparecimento de folha, fração de maior interesse da pastagem.

Cortes menos frequentes permitiram maior crescimento e desenvolvimento das plantas e, por consequência, maior distúrbio logo após a desfolha. Os maiores filocronos registrados refletem, provavelmente, necessidade de maior investimento (graus-dia) em estruturas de adaptação da planta aos processos intermitentes de desfolha adotados (renovações de raízes, adaptação de folhas a maior intensidade luminosa, entre outros fatores de estresse) em detrimento ao aparecimento de novas folhas (Pedroso et al., 2009). Esse fato foi ainda mais evidente para o segundo corte, com menor frequência entre desfolhas, pois nesta ocasião maior número de plantas atingiu o estágio reprodutivo. Quando as plantas estão neste estágio, sua prioridade passa a ser a produção de inflorescências e posterior formação e enchimento de sementes, e não mais formação e emissão de folhas. Além disso, segundo Van Esbroeck et al. (1997), há relação direta entre filocrono e florescimento, ou seja, à medida que as plantas forrageiras iniciam sua fase reprodutiva, os valores de filocrono se tornam maiores.

Tabela 1 - Taxa de aparecimento de folhas e filocrono em trevo-persa submetido a dois cortes de avaliação

\begin{tabular}{cccc}
\hline $\begin{array}{l}\text { Frequência de desfolhação } \\
\text { (número de folhas surgidas) }\end{array}$ & $\begin{array}{c}\text { Frequência de } \\
\text { desfolhação (dias) }\end{array}$ & $\begin{array}{c}\text { Taxa de aparecimento } \\
\text { de folhas (folhas/graus-dia) }\end{array}$ & $\begin{array}{c}\text { Filocrono } \\
\text { (graus-dia/folha) }\end{array}$ \\
\hline 4 folhas & 24,5 & $0,021 \mathrm{a}$ & $47,11 \mathrm{~b}$ \\
5 folhas & 32,5 & $0,019 \mathrm{~b}$ & $50,98 \mathrm{~b}$ \\
6 folhas & 38,5 & $0,017 \mathrm{c}$ & $60,87 \mathrm{a}$ \\
\hline
\end{tabular}

Médias seguidas pela mesma letra minúscula na coluna não diferem entre si pelo teste Tukey a $5 \%$. 
Houve efeito tanto da intensidade como da frequência de desfolhação sobre as taxas de alargamento e alongamento de folíolos (Tabela 2).

Para as taxas de alargamento e alongamento de folíolos, maiores valores foram obtidos nos intervalos de 4 e 5 folhas surgidas. A menor frequência de desfolhas possibilita maior dreno fisiológico da planta anual para formação de raízes, colmos e órgãos reprodutivos em detrimento de folhas (Pedroso et al., 2009). Todavia, como a metodologia adotada para se obterem esses valores foi a partir da relação entre o somatório de toda expansão das lâminas foliares (cm) e a soma térmica do período de desfolhas, houve um intervalo de tempo entre o florescimento dos ramos e a desfolha seguinte, com isso, nestes ramos, não havia qualquer expansão de folhas.

A maior intensidade de desfolha promoveu maior remoção de folhas, desta forma, ocorreram maiores taxas de alargamento e alongamento de folíolos da planta, com os objetivos de repor rapidamente sua área foliar e elevar a interceptação de luz e a atividade fotossintética (Pontes et al., 2004). Além disso, a maior renovação do pasto quando manejado em intensidades maiores, aliada à melhora da penetração de luz no interior do dossel, pode ter contribuído para aumentar os valores das taxas de alargamento e alongamento de folíolos.

Houve efeito das frequências de desfolhação sobre a largura e o comprimento de folíolos, o número de ramificações e a altura final de plantas (Tabela 3 ).

Nos menores períodos entre desfolhas, prevaleceram folhas de maior dimensão, comprimento e largura, por estarem alocadas em ordem intermediária de inserção na haste, já que as plantas ainda se encontravam no estágio vegetativo. As primeiras folhas de uma haste, seminais, possuem pequenas dimensões, logo, aumentam progressivamente suas dimensões até atingir inserção intermediária da haste. Logo após, nos níveis de inserção posteriores, as dimensões das folhas tornam a reduzir (Gomide \& Gomide, 2000). Segundo Gladstones \& Collins (1984), em Trifolium subterraneum L., os folíolos produzidos depois do florescimento começam progressivamente a diminuir de tamanho, ficam mais estreitos e mais triangulares. Stockdale (1994) complementa que folhas produzidas após o início do florescimento do trevo-persa eram menores e os pecíolos mais curtos.

$\mathrm{O}$ número de ramificações $/ \mathrm{m}^{2}$ foi maior no menor intervalo de corte, provavelmente devido à maior taxa de aparecimento de folhas neste intervalo. A taxa de aparecimento de folhas tem relação direta com o número ou a densidade de ramificações, já que cada folha formada representa o surgimento de um novo fitômero, ou seja, a geração de novas gemas axilares (Nabinger, 2001), que podem permanecer dormentes ou se diferenciar em novas estruturas vegetativas ou reprodutivas. Entre outros fatores, essa diferenciação depende, especialmente, da exposição das gemas axilares à radiação luminosa. Logo, nas maiores frequências de desfolha estudadas, provavelmente ocorreu maior interceptação de luz por essas gemas, o que auxiliou no melhor entendimento da verificação das maiores densidades de ramos por área nestes tratamentos.

Tabela 2 - Taxa de alargamento e alongamento de folíolos em trevo-persa submetido a dois cortes de avaliação

\begin{tabular}{|c|c|c|c|c|}
\hline \multirow[b]{2}{*}{ Intensidade de desfolhação } & \multicolumn{3}{|c|}{ Frequência de desfolhação } & \multirow[b]{2}{*}{ Média } \\
\hline & 4 folhas & 5 folhas & 6 folhas & \\
\hline \multicolumn{5}{|c|}{ Taxa de alargamento de folíolos (cm/graus-dia) } \\
\hline $5 \mathrm{~cm}$ & 0,00056 & 0,00039 & 0,00021 & $0,00039 a$ \\
\hline $10 \mathrm{~cm}$ & 0,00034 & 0,00028 & 0,00018 & $0,00027 b$ \\
\hline Média & $0,00045 \mathrm{~A}$ & $0,00033 \mathrm{~A}$ & $0,00019 \mathrm{~B}$ & \\
\hline \multicolumn{5}{|c|}{ Taxa de alongamento de folíolos (cm/graus-dia) } \\
\hline $5 \mathrm{~cm}$ & 0,00101 & 0,00068 & 0,00049 & $0,00073 \mathrm{a}$ \\
\hline $10 \mathrm{~cm}$ & 0,00071 & 0,00064 & 0,00036 & $0,00057 \mathrm{~b}$ \\
\hline Média & $0,00086 \mathrm{~A}$ & $0,00066 \mathrm{~B}$ & $0,00043 \mathrm{C}$ & \\
\hline
\end{tabular}

Médias seguidas pela mesma letra, maiúscula na linha e minúscula na coluna, não diferem $(\mathrm{P}<0,05)$ entre si pelo teste Tukey.

Tabela 3 - Largura e comprimento de folíolos, número de ramificações e altura final de plantas em trevo-persa submetido a dois cortes de avaliação

\begin{tabular}{ccccc}
\hline $\begin{array}{l}\text { Frequências de } \\
\text { desfolhação }\end{array}$ & $\begin{array}{c}\text { Largura de } \\
\text { folíolos }(\mathrm{cm})\end{array}$ & $\begin{array}{c}\text { Comprimento de } \\
\text { folíolos }(\mathrm{cm})\end{array}$ & $\begin{array}{c}\text { Número de ramificações } \\
\left.\text { (ramificações.m }{ }^{-2}\right)\end{array}$ & $\begin{array}{c}\text { Altura final de } \\
\text { plantas }(\mathrm{cm})\end{array}$ \\
\hline 4 folhas & $1,22 \mathrm{a}$ & $1,90 \mathrm{a}$ & $2600 \mathrm{a}$ & $8,83 \mathrm{c}$ \\
5 folhas & $1,14 \mathrm{a}$ & $1,81 \mathrm{a}$ & $2215,6 \mathrm{~b}$ & $15,43 \mathrm{~b}$ \\
6 folhas & $1,00 \mathrm{~b}$ & $1,68 \mathrm{~b}$ & $1876 \mathrm{~b}$ & $19,21 \mathrm{a}$ \\
\hline
\end{tabular}

Médias seguidas pela mesma letra minúscula na coluna não diferem entre si pelo teste Tukey $5 \%$. 
Ocorreu aumento da altura das plantas (AP) de acordo com o período de descanso entre desfolhas (Tabela 3). A maior altura observada no intervalo de 6 FS pode ser explicada pelo fato de as plantas terem mais tempo para crescimento. Em trabalhos realizados na Turquia para comparar linhagens de trevo-persa, Erdemli et al. (2007), Zohary (1970) e Lacy et al. (2003) encontraram alturas de plantas, crescendo livremente, que variavam de 26 a $59 \mathrm{~cm}$. Esses valores são superiores aos encontrados no presente trabalho, provavelmente porque plantas foram submetidas a tratamentos de corte.

$\mathrm{O}$ número de folhas vivas abertas variou com a intensidade e a frequência de desfolha (Tabela 4). A menor remoção de folhas na altura residual de $10 \mathrm{~cm}$ promoveu maior numero de folhas vivas abertas, que aumentou também com o acréscimo no intervalo entre desfolhas $(4 ; 5$ e 6 folhas surgidas). Conforme citado anteriormente, cortes menos frequentes influenciaram na passagem para o estágio reprodutivo. Segundo Stockdale (1994), quando as plantas se aproximam do estágio reprodutivo, o número de folhas aumenta. Erdemli et al. (2007), em plantas crescendo livremente na Turquia, encontraram no ramo principal entre 5,5 e 9 folhas vivas por ramificação quando as plantas atingiram 50\% de florescimento. Já Tekeli \& Ateş (2002), em linhagens de trevo-persa no período reprodutivo, encontraram de 7,8 a 10,1 folhas no caule principal. Os resultados encontrados neste estudo, embora as plantas tenham sido submetidas a corte, são similares aos encontrados pelos pesquisadores da Turquia. Dependendo do manejo imposto ao pasto, podem ocorrer variações nas características morfológicas. Além disso, segundo Erdemli et al. (2007), essas variações nas plantas de trevopersa podem ocorrer em função da localização geográfica, do tempo de condução dos experimentos e dos genótipos estudados.

Para produção de matéria seca, houve interação entre as frequências e intensidades de desfolha (Tabela 5).

A maior produção de forragem foi obtida na intensidade de $5 \mathrm{~cm}$ no maior intervalo de cortes. Esse resultado pode ser atribuído à maior remoção de área foliar e maior taxa de expansão das folhas (alargamento e alongamento) na maior intensidade de desfolha, bem como ao maior acúmulo de colmo e inflorescência quando foi permitido o aparecimento de 6 folhas entre desfolhas. Segundo Stockdale (1994), o número de pecíolos (folhas) e o alongamento dos entrenós são mais importantes na obtenção de altos rendimentos, porém, conforme descrito por Davies (1988), ocorre maior participação de caules na composição da matéria seca total quando as plantas estão na fase reprodutiva, o que tende a diminuir a qualidade da forragem, fato confirmado por Stockdale (1992) em experimento conduzido na Austrália para avaliação de períodos de até 12 semanas entre desfolhas.

A relação folha/caule foi maior no menor intervalo de cortes e não diferiu entre as intensidades de desfolha (Tabela 5). Embora apresentando maior número de folhas vivas nos maiores intervalos, a relação folha/caule é menor, devido ao menor tamanho dos folíolos, principalmente os produzidos no intervalo de 6 folhas, e ao maior percentual

Tabela 4 - Número de folhas vivas abertas em trevo-persa submetido a dois cortes de avaliação

\begin{tabular}{lccc}
\hline & \multicolumn{3}{c}{ Frequências de desfolhação } \\
\cline { 2 - 4 } Intensidade de desfolhação & 4 folhas & 5 folhas & 6 folhas \\
\hline & Número de folhas vivas abertas (folhas/ramificação) & 7,12 \\
$5 \mathrm{~cm}$ & 4,87 & 6,5 & $6,16 \mathrm{~b}$ \\
$10 \mathrm{~cm}$ & 4,81 & 7,06 & 6,62 \\
Média & $4,84 \mathrm{C}$ & $6,78 \mathrm{~B}$ & $7,87 \mathrm{~A}$ \\
\hline
\end{tabular}

Médias seguidas pela mesma letra, maiúscula na linha, não diferem $(\mathrm{P}<0,05)$ entre si pelo teste Tukey.

Médias seguidas pela mesma letra, minúscula na coluna, não diferem $(\mathrm{P}<0,05)$ entre si pelo teste Tukey.

Tabela 5 - Produção de matéria seca e relação folha/caule em trevo-persa submetido a dois cortes de avaliação

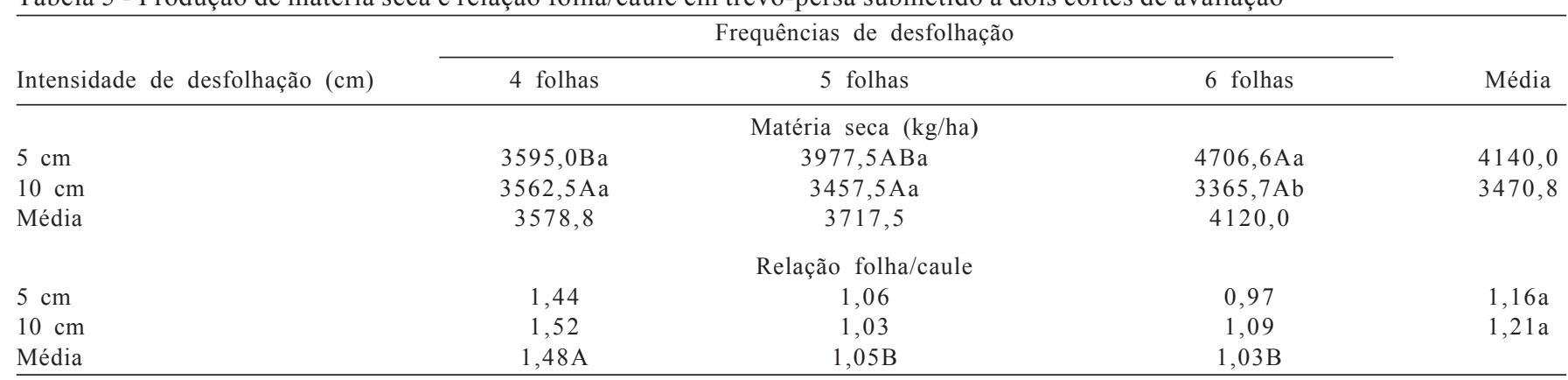

Médias seguidas pela mesma letra maiúscula na linha e minúscula na coluna não diferem $(\mathrm{P}<0,05)$ entre si pelo teste Tukey. 
de inflorescências e de caules. Desse modo, pode-se inferir que a qualidade da forragem no maior intervalo de desfolhas foi menor, provavelmente em função da maior participação de caules e flores. Essas frações determinam menor qualidade da forragem, devido ao maior teor de fibra, o que afeta negativamente a digestibilidade (Abreu et al., 2004) e o consumo da matéria seca (Wilson, 1982). No entanto, como o trevo-persa é uma forrageira de ciclo metabólico C3, mesmo em estádio de pré-florescimento ou início de florescimento, seu valor nutricional se assemelha ao de gramíneas de estação quente em estádio vegetativo.

Quanto à produção de forragem, no ambiente de origem (Paquistão), Nazir \& Farrukh (1985) relataram rendimentos de 11,2 t/ha matéria seca de trevo-persa em intervalo de cortes de 30 dias, produção muito superior à encontrada neste trabalho. Por outro lado, a produção de $4.140 \mathrm{~kg} \mathrm{MS} / \mathrm{ha}$ obtida com a maior intensidade de desfolha e menor frequência de desfolhas (Tabela 5) é muito semelhante à obtida por Gomes \& Reis (1999) e Costa et al. (2005) em condições ambientais muito semelhantes às do atual estudo. Maia et al. (2000), também em solos hidromórficos no sul do Rio Grande do Sul (RS), demonstraram a possibilidade de produção de até 5,9 t/ha de matéria seca.

No Sul do Rio Grande do Sul, durante a entressafra da cultura do arroz, é bastante comum o solo permanecer em pousio, ou seja, sem cultivo de espécies de estação fria, em decorrência de diversos fatores, entre eles, a má-drenagem do solo, o que inviabiliza o cultivo da grande maioria das espécies. Desse modo, após a colheita do arroz, o gado consome a resteva associada à vegetação nativa ou naturalizada, que se desenvolve juntamente com o arroz durante a estação quente. Essas espécies praticamente paralisam seus crescimentos durante as estações frias e apresentam baixa qualidade forrageira. Desse modo, a introdução de uma espécie forrageira que produza mais de $4 \mathrm{t} \mathrm{MS/ha} \mathrm{durante} \mathrm{essas} \mathrm{estações} \mathrm{frias,} \mathrm{com} \mathrm{valor} \mathrm{nutritivo}$ superior ao das nativas, é uma contribuição significativa nos sistemas de produção vegetal do Sul do Brasil. Destaca-se que o trevo-persa pertence a uma família bastante distinta do arroz, Fabaceae, o que contribui significativamente para a descontinuidade de ciclos de doenças, pragas e plantas daninhas no ambiente de produção.

\section{Conclusões}

Não foram observadas diferenças entre as duas variedades de trevo-persa para as variáveis analisadas. $\mathrm{O}$ manejo de desfolha afeta as características morfogênicas, estruturais e a produção de forragem do trevo-persa.
Maior intensidade e menor frequência de desfolha determinam maior produção de forragem, enquanto maiores frequências de desfolha determinam, especialmente, maior aparecimento, expansão e participação de folhas no dossel da pastagem.

\section{Referências}

ABREU, J.B.R.; CÓSERA, A.C.; DEMINICIS, B.B. et al. Avaliação da produção de matéria seca, relação folha/colmo e composição químico-bromatológica de Brachiaria humidicola (Rendle), submetida a diferentes idades de rebrota e doses de nitrogênio e potássio. Revista Universidade Rural: Série Ciência da Vida, v.24, p.135-141, 2004.

CARÁMBULA, M. Pasturas y forrajes: manejo, persistencia y renovación de pasturas. Montevideo: Editorial Hemisferio Sur, 2004. v.3. 413 p.

COSTA, N.L.; REIS, J.C.L.; RODRIGUES, R.C. et al. Trevo-persa - uma forrageira de duplo propósito. Pelotas: Embrapa Clima Temperado, 2005. 3p. (Comunicado Técnico, 116).

DAVIES, A. The regrowth of grass swards. In: JONES, M.B.; LAZENBY, A. (Eds.). The grass crop: Its physiological basis of production. London: Chapman and Hall, 1988. p. $85-127$.

ERDEMLI, S.; ÇOLAK, E.; KENDIR, H. Determination of some plant and agricultural characteristics in persian clover (Trifolium resupinatum L.). Tarim Bilimleri Dergisi, v.13, n.3, p.240-245, 2007.

GLADSTONES, J.S.; COLLINS, W.J. Naturalized subterranean clover strains of Western Australia. Perth: Western Australian Departament of Agriculture, 1984. 52p. (Technical Bulletin, 64).

GOMES, J.F.; REIS, J.C.L. Produção de forrageiras anuais de estação fria no litoral sul do Rio Grande do Sul. Revista Brasileira de Zootecnia, v.28, n.4, p.668-674, 1999.

GOMIDE, C.A.M.; GOMIDE, J.A. Morfogênese de cultivares de Panicum maximum Jacq. Revista Brasileira de Zootecnia, v.29, n.2, p.341-348, 2000.

IANNUCCI, A.; TERRIBILE, M.R.; MARTINIELLO, P. Effects of temperature and photoperiod on flowering time of forage legumes in Mediterranean environment. Field Crops Research, v.106, p.156-162, 2008

LACY, J.; DEAR, B.; SANDRAL, G. [2003]. Persian clover. Agfact, NSW Agriculture. Disponível em: <http://www.agric.nsw.gov.au/ -reader/pastvarieties/p2522.htm> Acesso em: 15 nov. 2008.

MAIA, M.S.; REIS, J.C.L.; CUNHA, C.P. Época de colheita de sementes de trevo persa cv. Kyambro. Pelotas: Embrapa Clima Temperado, 2000. 2p. (Recomendação Técnica, 19).

MAZZANTI, A. Adaptacion de espécies forrageras a la desfoliacion. In: SIMPÓSIO SOBRE AVALIAÇÃO DA PASTAGEM COM ANIMAIS. Maringá, 1997. Anais... Maringá: Cooper Graf. Artes Gráficas Ltda., 1997. p.75-84.

MISSISSIPI STATE UNIVERSITY - MSU. [2010]. Mississipi forages. Disponível em: <http://msucares.com/crops/forages/ legumes/cool/persianclover.html> Acesso em: 21 jan. 2011.

NABINGER, C.; PONTES, L.S. Morfogênese de plantas forrageiras e estrutura do pasto. In: REUNIÃO ANUAL DA SOCIEDADE BRASILEIRA DE ZOOTECNIA, 38., 2001, Piracicaba. Anais... Piracicaba, 2001. p.755-771.

NAZIR, M.; FARRUKH, H.S. Studies on persian clover (Trifolium resupinatum) Part I.: Effect of harvesting intervals on the crop yield and its total nitrogen. Plant Foods for Human Nutrition, v.35, p.51-56, 1985.

PEDROSO, C.E.S.; MONKS, P.L.; FERREIRA, O.G.L. et al. Características morfogênicas de milheto sob lotação rotacionada 
com diferentes períodos de descanso. Revista Brasileira de Zootecnia, v.38, n.12, p.2311-2319, 2009.

PONTES, L.S.; CARVALHO, P.C.F.; NABINGER, C. et al. Fluxo de biomassa em pastagem de azevém anual (Lolium multiflorum Lam.) manejada em diferentes alturas. Revista Brasileira de Zootecnia, v.33, n.3, p.529-537, 2004.

REIS, J.C.L. Origem e características de novos trevos adaptados ao sul do Brasil. Pelotas: Embrapa Clima Temperado, 2007. 29p. (Documento, 184).

SCIVITTARO, W.B.; MATTOS, M.L.T.; MARTINS, J.F.S. Uso de coberturas de solo como fonte de nitrogênio para sistema de produção orgânica de arroz irrigado. Revista Brasileira de Agroecologia, v.2, n.1, p.1078-1081, 2007.

STOCKDALE, C.R. Effects of frequency and height of defoliation on the production of a persian clover - annual ryegrass sward. Australian Journal of Experimental Agriculture, n.32, p.339-344, 1992.

STOCKDALE, C.R. Influence os defoliation on some aspects of regrowth and senescence of persian clover herbage grown in pots. Australian Journal of Experimental Agriculture, n.34, p.213-221, 1994.
STRECK, E.V.; KAMPF, N.; DALMOLIN, R.S.D. et al. Solos do Rio Grande do Sul. 2.ed. Porto Alegre: EMATER/RS - ASCAR, 2008. 222p.

SUTTIE, J.M. [1999]. Trifolium resupinatum (Persian clover). Disponível em: <http://www.fao.org/ag/AGP/AGPC/doc/ GBASE/data/Pf000415.htm> Acesso em: 24 jan. 2011.

TEKELI, A.S.; ATEŞ, E. [2002]. Adi fið (Vicia sativa L.) ve Ýran üçgülü (Trifolium resupinatum L.) hatlarýnda bazý verim öðelerinin varyasyonu ve kalýtýmý. Disponível em: $<$ http://www.trakya.edu.tr/Enstituler/FenBilimleri/Dergi/ arsiv/2002-1/09Al.pdf $>$ Acesso em: 24 jan. 2011.

Van ESBROECK, G.A.; HUSSEY, M.A.; SANDERSON, M.A. Leaf appearance rate and final leaf number of switchgrass cultivars. Crop Science, v.37, p.864-870, 1997.

WILSON, J.R. Environmental and nutritional factors affecting herbage quality. In: HACKER, B. (Ed.) Nutritional limits to animal production from pastures. Farnham Royal: CAB, 1982. p.111-113.

ZOHARY, M. Trifolium L. In: DAVIS, P.H. (Ed.) Flora of Turkey and the East Aegaen islands. Edinburgh: Edinburgh University Press, 1970. v.3, p.412-413. 